Canadian

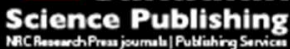

Canadian Journal of Zoology Revue canadienne de zoologie

\title{
Population- and individual-level prey selection by a solitary predator, as determined with two estimates of prey availability
}

\begin{tabular}{|r|l|}
\hline Journal: & Canadian Journal of Zoology \\
\hline Manuscript ID & cjz-2015-0092.R2 \\
\hline Manuscript Type: & Article \\
\hline Date Submitted by the Author: & 22-Jan-2016 \\
\hline Complete List of Authors: & $\begin{array}{l}\text { Elbroch, L; Panthera, } \\
\text { Lendrum, Patrick; Panthera, } \\
\text { Robinson, Hugh; Panthera USA, } \\
\text { Quigley, Howard; Panthera, }\end{array}$ \\
\hline Keyword: & $\begin{array}{l}\text { Puma concolor, puma, FORAGING < Discipline, PREDATION < Discipline, } \\
\text { diet, niche, prey selection }\end{array}$ \\
\hline
\end{tabular}

\section{SCHOLARONE"}

Manuscripts 
Population- and individual-level prey selection by a solitary predator, as determined with two estimates of prey availability

L. Mark Elbroch (LME), Patrick E. Lendrum (PEL), Hugh Robinson (HR), Howard B. Quigley (HBQ)

LME, Panthera, 8 West 40th Street, 18th Floor, New York, NY, 10018.

(melbroch@panthera.org)

PEL, Panthera, 8 West 40th Street, 18th Floor, New York, NY, 10018. (lendpatr@isu.edu)

HR, Panthera, 8 West 40th Street, 18th Floor, New York, NY, 10018. (hrobinson@panthera.org)

HBQ, Panthera, 8 West 40th Street, 18th Floor, New York, NY, 10018. (hquigley@panthera.org)

\section{*Corresponding author:}

L. Mark Elbroch, PO Box 27, Kelly, WY, 83011, USA

Tel: (307) 200-4928

Email:melbroch@panthera.org 


\title{
Population- and individual-level prey selection in a solitary predator, as determined with two estimates of prey availability
}

L. M. Elbroch, P. E. Lendrum, H. Robinson, H. B. Quigley

\begin{abstract}
Prey selection is exhibited by predator populations that kill a prey species disproportionate to its availability, or alternatively, individual predators that select prey disproportionate to the mean selection exhibited by their populations. Prey selection is a simple calculation when one can determine prey availability, however, measuring prey availability is challenging. We compared population- and individual-level prey selection as determined with two measures of prey availability for five ungulate species killed by pumas (Puma concolor (Linneus, 1771)) in the Southern Yellowstone Ecosystem, USA: 1) annual prey counts, and 2) total prey killed by marked pumas. We also tested whether individual pumas in the population exhibited a narrower dietary niche breadth as compared to their population as a whole. The two methods yielded different estimates of prey availability, and highlighted the need to consciously match prey availability estimates with appropriate ecological questions. Prey counts may have over estimated elk (Cervus canadensis (Erxleben, 1777)) abundance and underestimated deer abundance, whereas predation data may have better captured the influence of prey size on pumaspecific prey vulnerability and availability. Prey counts were the more appropriate metric for analyzing population-level prey selection, or differences in interspecific foraging, whereas total prey killed was the more appropriate metric for intraspecific comparisons.
\end{abstract}

Key words: diet, niche, prey availability, prey selection, puma, Puma concolor, Yellowstone 


\section{Introduction}

Prey selection is defined in two ways: 1) as exhibited by predator populations that kill a prey species disproportionate to its availability (Backwell et al.1998; Hayward et al. 2005), or 2) as exhibited by individual predators that select prey disproportionate to the mean selection exhibited by their populations (Pettorelli et al. 2011; Elbroch and Wittmer 2013). This dichotomy in defining prey selection creates opportunities to address both intraspecific and interspecific ecology. Population-level prey selection is indispensable in determining functional responses, describing species niches, and understanding interspecific competition (Holt and Lawton 1994; Harihar et al. 2011; Wittmer et al. 2014). Analyses of individual-level prey selection provide researchers the opportunity to identify keystone individuals (Modlmeier et al. 2014) and individuals exhibiting different behavioral traits (e.g., behavioral syndromes; Sih et al., 2012), as well as some tools useful in addressing the management of specialist predators threatening rare prey and livestock (Festa-Bianchet et al. 2006; Elbroch and Wittmer 2013; Wittmer et al. 2014). Further, individual-level prey selection provides researchers the opportunity to study the ecological context supporting intraspecific niche variation. If we define "niche" as the diet (resource use) of a particular species (e.g., Araujo et al. 2011), individuallevel prey selection is equivalent to individuals exhibiting a smaller dietary niche breadth as compared with the broader niche breadth exhibited by the population (Bolnick et al. 2003; Bolnick et al. 2011; Pettorelli et al. 2011).

Prey selection is a simple calculation when one has data on prey availability and the number of prey killed by a predator population. Determining prey availability, or the correct metric of prey availability to match one's ecological questions, however, can be challenging, especially for cryptic, wide-ranging species. Indeed, prey availability is influenced by predator 
size, perceptions, and behaviors, as well as prey size, vulnerability, and evasion behaviors (Greene 1986; Backwell et al. 1998; Molinari-Jobin et al. 2004; Owen-Smith 2008; Nilsen et al. 2009). For example, wolves (Canis lupus (Linneus, 1758)) are coursing, social predators that select disadvantaged prey in areas of limited structural complexity where they can test their prey's condition (Husseman et al. 2003; Peterson and Ciucci 2003), whereas pumas (Puma concolor (L., 1771)) are solitary stalk-and-pounce predators that select prey opportunistically (i.e., of any health) in areas where structural complexity (e.g., slope, trees, boulders) provide them an advantage (Husseman et al. 2003; Atwood et al. 2007). Therefore, the prey available to wolves and pumas in the same region are different because of their distinctive hunting strategies. This comparison emphasizes that prey availability in natural systems is unlikely equivalent to prey counts, except in rare instances, but rather an elusive, unquantifiable, evolving resource, varying by season and locale, and influenced by numerous other variables determined by both predators and prey (Backwell et al. 1998).

When a researcher's objective is to determine whether a population of predator species selects for or against particular prey, or whether two competitive species select for different prey in the same region, it is logical to define prey availability with estimates of total prey on the landscape (e.g., visual counts along transects following methods for Distance sampling; Harihar et al. 2011). Determining selection for populations can be an important first step in creating additional research hypotheses that might address which ecological variables drive observed selection (e.g., predator or prey morphology).

We suggest a better metric for prey availability when studying individual-level prey selection is total prey killed by the predator population. In this way, individual prey selection is a measure of how different an individual's prey selection is from the mean prey selection exhibited 
by the predator population. Mean prey selection exhibited by a predator population already accounts for variation in prey availability due to predator-specific prey vulnerabilities, such as those described above for wolves and pumas. Therefore, we can account for variation due to predator-specific prey availability before beginning within-population comparisons between individuals by utilizing total prey killed as the reference for prey availability; this focuses the analysis on the comparison among individual predators more directly.

Here, we describe population- and individual-level prey selection for five ungulate species killed by pumas in the Southern Yellowstone Ecosystem (SYE), northwest Wyoming, as determined from two measures of prey availability employed in predation studies: 1) from annual prey counts, and 2) from total prey killed by marked pumas. Initially, we compared the two estimates of availability to determine whether they were equivalent. Then we employed the appropriate metric in our different analyses. We hypothesized that pumas as a population would select for elk (Cervus canadensis (Erxleben, 1777)), the most abundant large prey species in the SYE, but that individual pumas would select prey differently. Further, we hypothesized that the niche breadth exhibited by individuals in the population would not be reflective of the puma population as a whole. In short, we hypothesized that neither prey selection or niche breadth exhibited by the puma population would be representative of the individuals in the population, but rather reflect a mean foraging strategy of diverse individuals selecting for and against different prey.

\section{Materials and methods}

Study area 
Our study area encompassed approximately $2,300 \mathrm{~km}^{2}$ of the Southern Yellowstone Ecosystem (SYE) north of Jackson, Wyoming. Elevations in the study area ranged from 1,800 $\mathrm{m}$ in the valleys to $>3,600 \mathrm{~m}$ in the mountains. Precipitation occurred mostly as snow, and maximum snow depths ranged from $100 \mathrm{~cm}$ at lower elevations to $>245 \mathrm{~cm}$ at intermediate and higher elevations $(\geq 2,000 \mathrm{~m})$. The study area supported a diverse community of large mammals. Carnivores included wolves, American black bears (Ursus americanus (Pallas, 1780)), grizzly bears (U. arctos (L., 1758)), coyotes (Canis latrans (Say, 1823)), and red foxes (Vulpes vulpes (L., 1758)). Ungulates included elk, mule deer (Odocoileus hemionus (Rafinesque, 1817)), moose (Alces alces (Gray, 1821)), bison (Bison bison (Hamilton Smith, 1827)), pronghorn (Antilocapra Americana (Ord, 1815)), bighorn sheep (Ovis canadensis (Shaw, 1804)), and a very small number of white-tailed deer (Odocoileus virginianus (Zimmermann, 1780)). Deer, elk, bighorn sheep, and pronghorn exhibited seasonal migrations (Elbroch et al. 2013) that influenced their seasonal availability to local pumas, and food subsidies provided to elk in winter by wildlife agencies have resulted in large aggregations of elk in winter in our study area. Additional details describing the study area can be found in Elbroch et al. (2013).

\section{Puma capture and collar programming}

Beginning in 2000, we captured pumas from late-November through March, when determining the presence of a puma was facilitated by snow. We used trailing hounds to force pumas to retreat to a tree where we could safely approach them. Pumas were immobilized with ketamine $(4.0 \mathrm{mg} / \mathrm{kg})$ and medetomidine $(0.07 \mathrm{mg} / \mathrm{kg})$, and then their temperature, heart rate and respiration were monitored at 5-min intervals while they were processed. Pumas were fit with either a VHF (Telonics, Mesa, AZ) or GPS collar (Telonics, Mesa, AZ; Televilt, Bandygatan, 
Sweden; Vectronics, Berlin, Germany; Lotek Wireless, Newmarket, Ontario, Canada). The effects of the capture drugs were reversed with Atipamezole $(0.375 \mathrm{mg} / \mathrm{kg})$. Our capture protocols for pumas followed those outlined in Quigley (2000), adhered to the guidelines outlined by the American Society of Mammalogists (Sikes et al. 2011), and were approved by the Jackson Institutional Animal Care and Use Committee (Protocol 027-10EGDBS-060210).

\section{Identifying puma prey}

We conducted site searches of all areas where triangulation of pumas wearing VHF collars revealed that they had not moved for $\geq 24$ hrs, or where spatially aggregated GPS points indicated a puma had remained in place for $\geq 8$ hours (Elbroch et al. 2013). Prey remains, including hair, skin, rumen (stomach), and bone fragments, were used to identify prey species; we looked for bite marks, wounds, and signs of struggles indicating that pumas were not scavenging. We included only ungulate prey in these analyses in order to mitigate biases associated with methods dependent upon VHF versus GPS data; GPS data facilitates greater success in finding small prey over VHF data (Merrill et al. 2010; Elbroch and Wittmer 2013).

\section{Prey availability}

We quantified prey availability using two methods: prey-count (Caughley 1977) and kill-count (Knopff and Boyce 2007; Tinker et al. 2012; Elbroch and Wittmer 2013). Pumas in the SYE killed different proportions of different prey in winter versus summer (Elbroch et al. 2013), and thus we quantified prey availability using the kill-count method for summer and winter separately. In contrast, prey-count censuses were only conducted in winter. Following Elbroch et 
al. (2013), we defined two 6-month seasons as: winter from Dec $1^{\text {st }}$ of one year through May $31^{\text {st }}$ of the next year, and summer as June $1^{\text {st }}$ through November $30^{\text {th }}$.

\section{Method 1: The prey-count method}

We quantified the availability of each prey species to the puma population as a whole as the proportion of the total ungulates counted within the study area (e.g., 0.47 for elk if they represented $47 \%$ of all ungulates on the landscape), as determined from annual Wyoming Game and Fish Department (WGFD) counts performed each winter from 2001 - 2013. We employed annual WGFD winter elk counts of the "Jackson herd" conducted via helicopter transects, WGFD mule deer counts conducted in Units $150,155,156$, moose counts in hunt areas 7, 14-15, 17-19, 28, 32, and bighorn sheep counts of the "Jackson herd" (\#107; WGFD Job Completion Reports, http://wgfd.wyo.gov/web2011/wildlife-1000496.aspx). Nearly every pronghorn migrated out of the study area in winter, but each year a variable number are seen in open areas, and documented anecdotally by the various agencies (ranging from 2-50). We used a mean of 20 pronghorn per year in total ungulate counts. We estimated winter availability for each species as their mean proportional representation $(\%)$ of the total number of ungulates counted over the course of the study.

\section{Method 2: The kill-count method}

The kill-count method utilized our prey database determined through actual field investigations as described above, after accounting for a variable number of kills documented for different pumas (Elbroch and Wittmer 2013). We summed the proportions of each prey killed by individual pumas to create total counts for each ungulate species killed by the puma population as a whole. Then, we used these prey totals to estimate prey availability as their proportional representation $(\%)$ of all ungulates in the puma population's diet in each season, as above for 
prey counts. We employed two-proportion z-tests to test whether species-specific prey availability as calculated by the two methods was different in winter, for which we had overlapping data.

Rarefaction to determine minimum sampling of prey killed by individual pumas

We employed rarefaction (Chao 1987; Krebs 2014) to determine the minimum prey that needed to be sampled per individual puma (Cantor et al. 2013) in order to capture prey species diversity. Rarefaction curves based upon our complete data set of all pumas and all kills asymptoted between 6-7 prey items per individual. Thus, we included individual pumas with data on $\geq 8$ ungulate prey killed in a given season to strengthen the biological relevance of our methods, as described further below.

\section{Testing for prey selection at the population level}

We employed Ivlev's electivity index (Ivlev 1961) and estimates of prey availability as determined with the prey-count method to determine whether pumas at the population-level selected for or against each of the five ungulate prey in winter as follows:

$\mathrm{Ei}=(\mathrm{ri}-\mathrm{ni}) /(\mathrm{ri}+\mathrm{ni})$, where $E i$ is the electivity index, $r i$ is the percentage of species $i$ in the diet and $n i$ is the available percentage of species $i$.

The electivity index returns a value between -1 and 1 . Values near 1 indicate selection for a prey type more than expected given its availability, and the closer the value to -1 , the stronger a prey species is selected against given its availability. We created $95 \%$ confidence intervals (CIs) for each respective prey type based on prey selection exhibited by pumas for which we had 
documented $\geq 8$ ungulate prey in a given season. We concluded that the puma population exhibited selection for or against a prey species if CIs for $E i$ values did not overlap 0.

\section{Testing for prey selection at the individual level}

We used chi-square goodness of fit tests to determine individual resource selection. We did this by comparing prey killed by individual pumas to prey availability as determined by total prey killed by the population. Only pumas for which we had documented $\geq 8$ ungulate prey in a given season were included in third order resource selection analyses to determine prey selection at the individual level. When results of the chi-square tests for individual pumas were significant, we created Bonferroni confidence intervals (CIs) for each prey for each puma to determine which prey proportions were statically different from those selected at the population-level (Byers et al. 1984). When CIs for individual pumas did not overlap with resource selection exhibited by the population, we considered the individual to select that prey in different proportions to the population.

Testing whether the dietary niche breadth of individuals matched that of the population We calculated the dietary diversity index (DDI) (Boyles and Storm 2007; adapted from Levin 1968) for individual pumas as follows:

$$
D D I=\frac{1}{\sum v_{i}^{2}}
$$

where $V$ is the proportion of a prey species killed by a puma. We then standardized DDI to express it on a scale from 0 to 1.0 (Krebs 2014) as follows:

$$
D D I_{s}=\frac{D D I-1}{n-1}
$$


where $n$ is number of prey types.

We calculated Levin's (1968) niche width $(B)$ to describe population-level selection: $B=\frac{1}{\sum p_{i}^{2}}$

where $p$ is the proportion of prey $i$ killed by all pumas and then standardized it as described above to express niche width on a scale of 0 to $1.0\left(B_{S}\right)$. To test whether niches of individual pumas were reflective of the puma population as a whole, we created $95 \%$ CIs for $B_{S}$ based upon individual DDIs. Then we determined whether DDI's for individual pumas fell within the CIs for $B_{S}$. When DDIs fell outside of the CIs, we determined that those pumas exhibited a niche width different than the population as a whole.

Hurlbert (1978) modified Levin's to account for prey availability, and we repeated the above analyses to test niche breadth for the population while accounting for prey availability based on the prey-count method. We tested individual DDIs against the population with prey availability as determined with the kill-count method:

$$
B_{h}=\frac{1}{\sum\left(\frac{p_{i}^{2}}{a_{i}}\right)}
$$

where $B_{h}$ is Hurlbert's diet breadth, $p$ is the proportion of prey $i$ killed by pumas, and $a$ is the proportion of total prey that is prey $i$. We standardized Hurlbert's diet breadth as follows (Krebs 2014):

$$
B_{h S}=\frac{B-a_{\min }}{1-a_{\min }},
$$

where $\mathrm{a}_{\min }$ was the smallest proportion of any prey observed. To test whether niches of individual pumas were reflective of the puma population as a whole, we created $95 \%$ CIs for $B_{h S}$ 
based upon individual DDIs. Then we determined whether DDI's for individual pumas fell within the CIs for $B_{h s}$. When DDIs fell outside of the CIs, we determined that those pumas exhibited a niche width different than the population as a whole.

\section{Results}

\section{Marked pumas and documented kills}

Between January, 2002, and November 1, 2013, we recorded 473 ungulates killed by 9 male and 23 female pumas during summers, and 656 ungulates killed by 11 males and 27 females in winters. We recorded $\geq 8$ prey for 4 males and 11 females during summers, and 7 males and 14 females during winters, and we utilized this subset of pumas for analyses of individual-level variation in prey selection.

Prey availability as determined by two methods

Prey availability varied by season and method. Summer prey availability as determined with the kill-count method was: $0.474 \pm 0.198$ elk, $0.394 \pm 178$ deer, $0.087 \pm 0.057$ moose, $0.019 \pm 0.034$ pronghorn, and $0.026 \pm 0.026$ bighorn sheep. Winter prey availability as determined by the preycount method likely overestimated elk availability and underestimated deer, pronghorn, and bighorn sheep as compared to the kill-count method (Table 1).

\section{Prey selection at the population level}

In winter, the puma population killed deer in proportion to their abundance, and selected against elk, moose, pronghorn, and bighorn sheep (Fig. 1). 
Prey selection at the individual level

In summer, three of 15 pumas selected deer more than the population mean, and one selected pronghorn more than the population mean (Table 2). In winter, seven pumas killed elk more than the population mean, and two pumas killed moose more than the population mean (Table 3).

Individual and population level niche breadths

In summer, standardized Levin's diet breath (which does not account for prey availability) for the puma population was 0.25 . We did not have summer prey counts with which to calculate Hurlbert's diet breadth. Of 15 pumas with $\geq 8$ prey recorded in summers, seven displayed dietary diversity index values (DDIs) different than the niche breadth of the puma population (Fig. 2).

In winter, standardized Levin's diet breath for the puma population was 0.15 . Adjusted for availability determined with the prey-count method, mean standardized Hurlbert's diet breath for the puma population was 0.54 for winters. Of 21 pumas with $\geq 8$ prey recorded in winters, 13 displayed DDIs different than the niche breadth of the puma population (Fig. 2), and 13 pumas displayed Hurlbert's niche breadths different than the niche breadth of the puma population.

\section{Discussion}

Estimating prey abundances to study population- and individual- level prey selection is difficult, given that prey availability varies with predator size and behaviors, prey size and behaviors, prey habitat selection, and prey evasion behaviors (Greene 1986; Backwell et al. 1998; Molinari-Jobin et al. 2004; Nilsen et al. 2009). The two metrics we tested yielded different estimates of prey 
availability, highlighting the need for careful consideration when selecting which estimate is appropriate for ecological questions at the population-level (e.g., Are pumas and wolves selecting different prey?) versus individual-level (e.g., Are some pumas specializing on livestock?). We measured puma population- and individual-level prey selection in winter using both the kill-count and prey-count methods of estimating prey availability, and individual prey selection in summer with the kill-count method.

In winter, the primary differences in prey availability as determined by the two methods were for elk and deer. The kill-count method estimated less elk availability than the prey-count method (77.9 vs 93.4\%), and in contrast, the kill-count method estimated higher deer availability than the prey-count method (12.4 vs. 0.9\%). Approximately 5,000-6,000 of the 12,000 elk counted annually by WDFG spend their winters in the wide-open grasslands along valley bottoms on supplemental feed grounds, far from suitable cover in which pumas stalk efficiently (Smith 2007, WGFD, http://wgfd.wyo.gov/web2011/wildlife-1000496.aspx). Therefore, the elk in these open grasslands were likely unavailable to pumas (sensu Husseman et al. 2003), positively biasing estimates of elk availability determined with the prey-count method. Deer estimates determined with annual prey counts were also likely negatively biased due to inconsistencies in the method used to count them, and the unstructured nature of annual deer counts (e.g., lack of sightability correction, D. Brimeyer, WGFD, pers. comm.). Higher deer availability, as estimated by the kill-count method, may better reflect actual numbers of deer in the study area, or be interpreted as support for the theory that prey size limits prey availability (and thus hunting success) for pumas. Adult deer rather than adult elk are considered the ideal prey size for pumas (Carbone et al. 1999; Husseman et al. 2003). Thus the larger estimate for 
deer determined through the kill-count method may incorporate the influence of prey size on puma-specific prey vulnerability and prey availability.

Correctly estimating prey availability for a wide-ranging carnivore with diverse dietary behaviors is perhaps near impossible. Nevertheless, when they are feasible, accurate prey counts to determine availability are more suited to measuring population-level prey selection. The goals of population-level analyses are often to determine to what extent one predator species chooses prey disproportionate to existing prey availability on the landscape, or differently from another predator species. In contrast, prey availability as determined by the kill-count method is more suited to within-population comparisons of intraspecific prey selection. Prey selection analyses using the kill-count method compare prey selection exhibited by individual predators against the population's mean prey selection, rather than against the availability of every potential prey for all predators. In this way, the kill-count method may intrinsically account for species-specific prey vulnerabilities, thus making within-population analyses comparing prey selection of individual predators more accurate.

Our results highlighted that niche breadth and prey selection characteristics describing entire carnivore populations can be misleading (e.g., Gómez-Ortiz and Monroy-Vilchis 2013), because they may not be reflective of most of the individual members of these populations (Fig. 2). Our work contributes to growing evidence that carnivore populations are composed of individuals that select for different prey and exhibit different niche breadths. (e.g., Ross et al. 1997; Festa-Bianchet et al. 2006; Knopff and Boyce 2007; Cavalcanti and Gese. 2010; Tinker et al. 2012; Elbroch and Wittmer 2013). Based on results utilizing availability determined with the kill-count method in summer, approximately half of marked pumas exhibited niche breadths 
different to their population, and in winter, two-thirds of individual pumas were different than the niche breadth of the entire population.

Intraspecific prey selection has significant implications for theoretical ecology, because predictive modeling of predator-prey dynamics that lack an understanding of the individual components making up the population are unlikely to be accurate (Bolnick et al. 2003; Pettoreli et al. 2011; Wittmer et al. 2014). Individual specialization influences population stability, explains predator-prey interactions, strengthens predator-prey modeling, drives competition scenarios, and influences the adaptive evolution of a species, given the variable influences of certain phenotypes exhibiting specific behaviors (Pettoreli et al. 2011; Bolnick et al. 2011; DiRienzo et al. 2013; Griffen 2014). For example, Wittmer et al. (2014) showed that models incorporating individual prey selection into predation scenarios predicted longer persistence probabilities of rare prey than models that did not include this variation.

Our results also have implications for applied conservation management and the management of carnivores that select for rare prey or livestock (Rominger 2007; Elbroch and Wittmer 2013). When researchers measure individual-level prey selection, they can determine whether stochastic predation of rare prey, as defined by Festa-Bianchet et al. (2006), is driven by individuals exhibiting prey selection or the population as a whole. For example, previous research reported that individual pumas have specialized on moose (Ross and Jalkotsky 1996), bighorn sheep (Festa-Bianchet et al. 2006), huemul deer (Hippocamelus bisulcus (Moliba, 1782)) (Wittmer et al. 2014), and North American porcupines (Erethizon dorsatum (L., 1758)) (Sweitzer et al.1997), and that the potential impact that relatively few specialist predators have on rare species in natural systems can be substantial (Elbroch and Wittmer 2013, Pettorelli et al. 2015). In our study, however, few pumas killed rare ungulates (moose, pronghorn, bighorn sheep) more 
than expected given their availability or more than the population norm, and in fact, almost every puma selected against rare prey given their availability in the SYE. Our results identified one puma that selected for pronghorn, and two that selected for moose (Tables 2 and 3).

Primary prey, which in the case of pumas is deer and elk, should be selected for regardless of their availability, while secondary prey should only be selected for when they are abundant (Hayward 2011). Thus, puma populations may always select against moose, bighorn sheep, and pronghorn, except in rare areas where they are abundant enough to distract from more ubiquitous elk and deer, or in exceptional cases when individual pumas exhibit an unexplainable preference (e.g., behavioral syndromes; Sih et al., 2012). Under current conditions in the SYE, pumas do not appear to be a threat to any rare prey. These results suggest that population-level management of pumas, such as increasing puma harvest quotas, will likely prove ineffective in addressing puma predation on any rare prey in the SYE, and supports the contention that targeted removals of specialist predators may be more effective in addressing predation on rare or secondary prey (Elbroch and Wittmer 2013; Peebles et al. 2013). Determining the effects of individual variation in prey selection on prey dynamics is an exciting, and as yet, rarely explored aspect of ecology with great potential for future inquiry (Wittmer et al. 2014; Pettorelli et al. 2015).

\section{Acknowledgements}

We thank our collaborators, including K. Murphy (Bridger-Teton NF), S. Cain (Grand Teton NP), T. Fuchs (WY Game and Fish), E. Cole (National Elk Refuge), and D. Craighead (Craighead Beringia South), as well as our supportive funders, the Summerlee Foundation, The Richard King Mellon Foundation, The Charles Engelhard Foundation, The Laura Moore 
Cunningham Foundation, Tim and Karen Hixon Foundation, National Geographic Society, The Norcross Wildlife Foundation, Inc., Earth Friends Conservation Fund, the Cougar Fund, The Bay Foundation, Michael Cline Foundation, Eugene V. and Clare E. Thaw Charitable Trust, Connemara Fund, Hogan Films, National Fish and Wildlife Foundation, Community Foundation of Jackson Hole, The Oregon Zoo Foundation, Mr. and Mrs. G. Ordway, Mr. and Mrs. M. Manship, Mr. and Mrs. N. Jannotta, Mr. L. Westbrook, Mr. and Mrs. S. Robertson, Mr. R. Comegys, and several anonymous foundation and individual donors. Thank you to H. Johnson for constructive criticisms of an early draft of the manuscript.

\section{References}

Atwood, T.C., Gese, E.M., and Kunkel, K.E. 2007. Comparative patterns of predation by cougars and recolonizing wolves in Montana's Madison Range. J. Wildl. Manage. 71: 10981106.

Araújo, M.S., Bolnick, D.I., and Layman, C.A. 2011. The ecological causes of individual specialization. Ecol. Lett. 14: 948-958.

Backwell, P.R.Y., O’Hara, P.D., and Christy, J.H. 1998. Prey availability and selective foraging in shorebirds. Anim. Behav. 55: 1659-1667.

Bolnick, D.I., Amarasekare, P., Araujo, M., Burger, R., Levine, J., Novak, M., Rudolf, V., Schreiber, S., Urban, M., and Vasseur, D. 2011. Why intraspecific trait variation matters in ecology. Trends Ecol. Evol. 26: 183-192.

Bolnick, D.I., Svanback, R., Fordyce, J.A., Yang, L.H., Davis, J.M., Hulsey, C.D., and Forister, M.L. 2003. The ecology of individuals: incidence and implications of individual specialization. Am. Nat. 161: 1-28. 
Boyles, J.G., and Storm, J.J. 2007. The Perils of Picky Eating: Dietary Breadth Is Related to Extinction Risk in Insectivorous Bats. PLoS ONE, 2: e672 doi:10.1371/journal.pone.0000672

Byers, C.R., Steinhorst, R.K., and Krausman, P.R. 1984. Clarification of a technique for analysis of utilization-availability data. J. Wildl. Manage. 48: 1050-1053.

Cantor, M., Pires, M.M., Longo, G.O., Guimarães, P. R., and Setz, E.Z.F. 2013. Individual variation in resource use by opossums leading to nested fruit consumption. Oikos, 122: 10851093.

Cavalcanti, S.M., and Gese, E.M. 2010. Kill rates and predation patterns of jaguars (Panthera onca) in the southern Pantanal, Brazil. J. Mammal. 91: 722-736.

Carbone, C., Mace, G.M., Roberts, S.C., and Macdonald, D.W. 1999. Energetic constraints on the diet of terrestrial carnivores. Nature, 402: 286-288.

Caughley, G. 1977. Analysis of vertebrate populations. Wiley-Interscience, New York, USA

Chao, A. 1987. Estimating the population size for capture-recapture data with unequal catchability. Biometrics, 43: 783-791.

DiRienzo, N., Pruitt, J.N., and Hedrick, A.V. 2013. The combined behavioural tendencies of predator and prey mediate the outcome of their interaction. Anim. Behav. 86: 317-322.

Elbroch, L.M., and Wittmer, H. 2013. The effects of puma prey selection and specialization on less abundant prey in Patagonia. J. Mammal. 94: 259-268.

Elbroch, L.M., Lendrum, P.E., Newby, J., Quigley, H. and Craighead, D. 2013. Seasonal foraging ecology of non-migratory cougars in a system with migrating prey. PLoS ONE, $\mathbf{8}$ : e83375 doi:10.1371/journal.pone.0083375 
Festa-Bianchet, M., Coulson, T., Gaillard, J.M., Hogg, J.T., and Pelletier, F. 2006. Stochastic predation events and population persistence in bighorn sheep. Proc. R. Soc. B, 273: 15371543.

Gómez-Ortiz, Y., and Monroy-Vilchis, O. 2013. Feeding ecology of puma Puma concolor in Mexican montane forests with comments about jaguar Panthera onca. Wildlife Biol. 9: 179187.

Greene, C.H. 1986. Patterns of Prey Selection: Implications of Predator Foraging Tactics. Am. Nat. 128: 824-839.

Griffen, B.D. 2014. Linking individual diet and fecundity in an omnivorous marine consumer. Oecologia, 174: 121-130.

Harihar, A., Pandav, B., and Goyal, S.P. 2011. Responses of leopard Panthera pardus to the recovery of a tiger Panthera tigris population. J. Anim. Ecol. 48: 806-814.

Hayward, M.W. 2011. Scarcity in the prey community yields anti-predator benefits. Acta Oecologia, 37: 314-320.

Hayward, H.W. and Graham I. H. Kerley. 2005. Prey preferences of the lion (Panthera leo). J. Zool. (Lond.) 267: 309-322.

Holt, R.D., and Lawton, J.H. 1994. The ecological consequences of shared natural enemies. Annu. Rev. Ecol. Syst. 25: 495-520.

Hurlbert, S.H. 1978. The measurement of niche overlap and some relatives. Ecology, 59: 67-77. Husseman, J.S., Murray, D.L., Power, G., Mack, C., Wenger, C.R., and Quigley, H. 2003. Assessing differential prey selection patterns between two sympatric large carnivores. Oikos, 101, 591-601. 
Ivlev, V.S. 1961. Experimental ecology of the feeding of fishes. Yale University Press, New Haven, CT.

Knopff, K.H., and Boyce, M.S. 2007. Prey specialization by individual cougar in multi-prey systems. In Transactions of the Seventy-Second North American Wildlife and Natural Resources Conference, Portland, OR, pp 194-210.

Krebs, C.J. 2014. Ecological methodology, 3rd ed. Benjamin Cummings, London.

Levins, R. 1968. Evolution in changing environments. Princeton University Press, Princeton, NJ.

Merrill, E., Zimmermann, H.S.B., McPhee, H., Webb, N., Hebblewhite, M., Wabakken, P., and Frair, J.L. 2010. Building a mechanistic understanding of predation with GPS-based movement data. Proc. Trans. R. Soc. B, 365: 2279-2288.

Modlmeier, A.P., Keiser, C.N., Watters, J.V., Sih, A., and Pruitt, J.N. 2014. The keystone individual concept: an ecological and evolutionary overview. Anim. Behav. 89: 53-62.

Molinari-Jobin, A., Molinari, P., Loison, A., Gaillard, J.M., and Brestenmoser, V. 2004. Life cycle period and activity of prey influence their susceptibility to predators. Ecography, 27: $323-329$.

Nilsen, E.B., Gaillard, J.M., Andersen, R., Odden, J., Delorme, D., van Laere, G., and Linnell, J.D.C. 2009. A slow life in hell or a fast life in heaven: demographic analyses of contrasting roe deer populations. J. Anim. Ecol. 78: 585-594.

Owen-Smith, N. 2008. Changing vulnerability to predation related to season and sex in an African ungulate assemblage. Oikos, 117: 602-610.

Peebles, K.A., Wielgus, R.B., Maletzke, B.T., and Swanson, M.E. 2013. Effects of Remedial Sport Hunting on Cougar Complaints and Livestock Depredations. PLoS ONE, 8: e79713 doi:10.1371/journal.pone.0079713 
Peterson, R.O., and Ciucci, P. 2003. The wolf as a carnivore. In Wolves: behaviour, ecology and conservation. Edited by L.D. Mech and L. Boitani. University of Chicago Press, Chicago, IL. pp. 104-130.

Pettorelli, N., Coulson, T., Durant, S.M., and Gaillard, J.M. 2011. Predation, individual variability and vertebrate population dynamics. Oecologia, 167: 305-314.

Pettorelli, N., Hilborn, A., Duncan, C., and Durant, S.M. 2015. Individual variability: the missing component to our understanding of predator-prey interactions. Adv. Ecol. Res. 52: 19-44.

Quigley, K. 2000. Immobilization and biological sampling protocols. Hornocker Wildlife Institute/Wildlife Conservation Society, Moscow, ID.

Rominger, E.M. 2007. Culling mountain lions to protect ungulate populations—-some lives are more sacred than others. In Transactions of the $72^{\text {nd }}$ North American Wildlife and Natural Resources Conference, Portland, OR. pp. 186-193.

Ross, P.I., and Jalkotzy, M. 1996. Cougar predation on moose in southwestern Alberta. Alces, 32: $1-8$.

Ross, P.I., Jalkotzy, M., and Festa-Bianchet, M. 1997. Cougar predation on bighorn sheep in southwestern Alberta during winter. Can. J. Zool. 75: 771-775.

Sih, A., Cote, J., Evans, M., Fogarty, S., and Pruitt, J. 2012. Ecological implications of behavioural syndromes. Ecol. Lett. 15: 278-289.

Sikes, R.S., Gannon, W.L., and the Animal Care and Use Committee of the American Society of Mammalogists 2011. Guidelines of the American Society of Mammalogists for the use of wild mammals in research. J. Mammal. 92: 235-253.

Smith, B.L. 2007. Migratory behavior of hunted elk. Northwest Sci. 81: 251-264. 
Sweitzer, R.A., Jenkins, S.H. and Berger, J. 1997. Near-Extinction of Porcupines by Mountain Lions and Consequences of Ecosystem Change in the Great Basin Desert. Conserv. Biol. 11: 1407-1417.

Tinker, M.T., Guimarães, P.R., Novak, M., Marquitti, F.M.D., Staedler, M., Bentall, G., and Estes, J.A. 2012. Structure and mechanism of diet specialization: testing models of individual variation in resource use with sea otters. Ecol. Lett. 15: 475-483.

Wittmer, H., Serrouya, R., Elbroch, M., and Marshall, A. 2013. Conservation Strategies for Species Affected by Apparent Competition. Conserv. Biol. 27: 254-60.

Wittmer, H.U., Hasenbank, M., Elbroch, M., and Marshall, A.J. 2014. Incorporating preferential prey selection and stochastic predation into population viability analysis for rare prey species. Biol. Conserv. 172: 8-14.

Woo, K.J., Elliott, K.H., Davidson, M., Gaston, A.J., and Davoren, G.K. 2008. Individual specialization in diet by a generalist marine predator reflects specialization in foraging behaviour. J. Anim. Ecol. 77: 1082-1091. 
Table 1. Winter prey availability as determined with the prey-count and kill-count methods, and the results of the two-proportions z-test to determine whether estimates were different for each of the 5 prey species. An (*) indicates a significant difference.

\begin{tabular}{lllll}
\hline Species & $\begin{array}{l}\text { Prey count } \\
(\mathbf{n}=\mathbf{1 2 0 2 3})\end{array}$ & $\begin{array}{l}\text { Kill-count } \\
\mathbf{( n = 6 5 6 )}\end{array}$ & z score & p-value \\
& $0.934 \pm 0.009$ & $0.779 \pm 0.140$ & -28.354 & $<0.001^{*}$ \\
\hline Elk & $0.009 \pm 0.005$ & $0.124 \pm 0.080$ & 36.814 & $<0.001^{*}$ \\
Deer & $0.032 \pm .0100$ & $0.038 \pm 0.120$ & 1.280 & 0.200 \\
Proose & $0.002 \pm .000$ & $0.005 \pm .030$ & 2.561 & $0.010^{*}$ \\
Bighorn sheep & $0.023 \pm 0.009$ & $0.054 \pm 0.060$ & 13.225 & $<0.001^{*}$ \\
\hline
\end{tabular}


Table 2. Results of the Chi-square analysis, associated Bonferroni confidence intervals, and prey availability as determined by the kill-count method, to determine intraspecific variation in summer prey selection. "F" in the "Puma" column indicates a female puma, and "M" a male. An “=” in the Kill Count column indicates the individual puma selected prey in proportion to selection exhibited by the population, a "+" indicates the puma selected a prey more than the population, and a "_"“ indicates that the individual selected a particular prey less than the population as a whole.

\begin{tabular}{|c|c|c|c|c|}
\hline Puma & Prey & $\begin{array}{l}\text { Bonf Z } \\
\text { Lower } \\
\text { Limit } \\
\end{array}$ & $\begin{array}{l}\text { Bonf Z } \\
\text { Upper } \\
\text { Limit } \\
\end{array}$ & Kill-count \\
\hline \multirow[t]{5}{*}{ F013 } & Elk & 0.429 & 0.793 & $0.470(=)$ \\
\hline & Deer & 0.157 & 0.509 & $0.390(=)$ \\
\hline & Moose & -0.002 & 0.002 & $0.090(-)$ \\
\hline & Pronghorn & -0.030 & 0.141 & $0.020(=)$ \\
\hline & Bighorn & -0.002 & 0.002 & $0.030(-)$ \\
\hline \multirow[t]{5}{*}{ F047 } & Elk & -0.074 & 0.408 & $0.470(-)$ \\
\hline & Deer & 0.592 & 1.074 & $0.390(+)$ \\
\hline & Moose & -0.006 & 0.006 & $0.090(-)$ \\
\hline & Pronghorn & -0.006 & 0.006 & $0.020(-)$ \\
\hline & Bighorn & -0.006 & 0.006 & $0.030(-)$ \\
\hline \multirow[t]{5}{*}{ F049 } & Elk & -0.019 & 0.685 & $0.470(=)$ \\
\hline & Deer & 0.315 & 1.019 & $0.390(=)$ \\
\hline & Moose & -0.008 & 0.008 & $0.090(-)$ \\
\hline & Pronghorn & -0.008 & 0.008 & $0.020(-)$ \\
\hline & Bighorn & -0.008 & 0.008 & $0.030(-)$ \\
\hline \multirow[t]{5}{*}{ F051 } & Elk & 0.009 & 0.261 & $0.470(-)$ \\
\hline & Deer & 0.667 & 0.955 & $0.390(+)$ \\
\hline & Moose & -0.002 & 0.002 & $0.090(-)$ \\
\hline & Pronghorn & -0.029 & 0.137 & $0.020(=)$ \\
\hline & Bighorn & -0.002 & 0.002 & $0.030(-)$ \\
\hline \multirow[t]{4}{*}{ F057 } & Elk & 0.025 & 0.410 & $0.470(-)$ \\
\hline & Deer & 0.430 & 0.875 & $0.390(+)$ \\
\hline & Moose & -0.003 & 0.003 & $0.090(-)$ \\
\hline & Pronghorn & -0.003 & 0.003 & $0.020(-)$ \\
\hline
\end{tabular}




\begin{tabular}{|c|c|c|c|c|}
\hline & Bighorn & -0.027 & 0.288 & $0.030(=)$ \\
\hline \multirow[t]{5}{*}{ F061 } & Elk & 0.108 & 0.365 & $0.470(-)$ \\
\hline & Deer & 0.395 & 0.696 & $0.390(=)$ \\
\hline & Moose & -0.001 & 0.001 & $0.090(-)$ \\
\hline & Pronghorn & 0.079 & 0.321 & $0.020(+)$ \\
\hline & Bighorn & -0.001 & 0.001 & $0.030(-)$ \\
\hline \multirow[t]{5}{*}{ F069 } & Elk & 0.082 & 0.687 & $0.470(=)$ \\
\hline & Deer & 0.229 & 0.848 & $0.390(=)$ \\
\hline & Moose & -0.005 & 0.006 & $0.090(-)$ \\
\hline & Pronghorn & -0.070 & 0.378 & $0.020(=)$ \\
\hline & Bighorn & -0.005 & 0.006 & $0.030(-)$ \\
\hline \multirow[t]{5}{*}{ F101 } & Elk & 0.304 & 0.649 & $0.470(=)$ \\
\hline & Deer & 0.351 & 0.696 & $0.390(=)$ \\
\hline & Moose & -0.002 & 0.002 & $0.090(-)$ \\
\hline & Pronghorn & -0.002 & 0.002 & $0.020(-)$ \\
\hline & Bighorn & -0.002 & 0.002 & $0.030(-)$ \\
\hline \multirow[t]{5}{*}{ F102 } & Elk & 0.375 & 1.025 & $0.470(=)$ \\
\hline & Deer & -0.025 & 0.625 & $0.390(=)$ \\
\hline & Moose & -0.007 & 0.007 & $0.090(-)$ \\
\hline & Pronghorn & -0.007 & 0.007 & $0.020(-)$ \\
\hline & Bighorn & -0.007 & 0.007 & $0.030(-)$ \\
\hline \multirow[t]{5}{*}{ F104 } & Elk & 0.407 & 1.093 & $0.470(=)$ \\
\hline & Deer & -0.093 & 0.593 & $0.390(=)$ \\
\hline & Moose & -0.009 & 0.009 & $0.090(-)$ \\
\hline & Pronghorn & -0.009 & 0.009 & $0.020(-)$ \\
\hline & Bighorn & -0.009 & 0.009 & $0.030(-)$ \\
\hline \multirow[t]{5}{*}{ F109 } & Elk & 0.171 & 0.598 & $0.470(=)$ \\
\hline & Deer & 0.360 & 0.794 & $0.390(=)$ \\
\hline & Moose & -0.003 & 0.003 & $0.090(-)$ \\
\hline & Pronghorn & -0.003 & 0.003 & $0.020(-)$ \\
\hline & Bighorn & -0.046 & 0.123 & $0.030(=)$ \\
\hline \multirow[t]{5}{*}{ M028 } & Elk & 0.073 & 0.816 & $0.470(=)$ \\
\hline & Deer & -0.019 & 0.685 & $0.390(=)$ \\
\hline & Moose & -0.088 & 0.533 & $0.090(=)$ \\
\hline & Pronghorn & -0.008 & 0.008 & $0.020(-)$ \\
\hline & Bighorn & -0.008 & 0.008 & $0.030(-)$ \\
\hline \multirow[t]{5}{*}{ M029 } & Elk & 0.360 & 0.794 & $0.470(=)$ \\
\hline & Deer & 0.206 & 0.640 & $0.390(=)$ \\
\hline & Moose & -0.003 & 0.003 & $0.090(-)$ \\
\hline & Pronghorn & -0.003 & 0.003 & $0.020(-)$ \\
\hline & Bighorn & -0.003 & 0.003 & $0.030(-)$ \\
\hline
\end{tabular}




\begin{tabular}{llrrr} 
M062 & Elk & 0.104 & 0.896 & $0.470(=)$ \\
& Deer & 0.104 & 0.896 & $0.390(=)$ \\
& Moose & -0.009 & 0.009 & $0.090(-)$ \\
& Pronghorn & -0.009 & 0.009 & $0.020(-)$ \\
M068 & Bighorn & -0.009 & 0.009 & $0.030(-)$ \\
& Elk & -0.074 & 0.408 & $0.470(-)$ \\
& Deer & 0.362 & 0.972 & $0.390(=)$ \\
& Moose & -0.006 & 0.006 & $0.090(-)$ \\
& Pronghorn & -0.074 & 0.408 & $0.020(=)$ \\
& Bighorn & -0.006 & 0.006 & $0.030(-)$ \\
\hline
\end{tabular}


1 Table 3. Comparative results of the Chi-square analyses, associated Bonferroni confidence

2 intervals, and prey availability as determined by the kill-count method, to determine intraspecific

3 variation in winter prey selection. "F" in the "Puma" column indicates a female puma, and "M" a

4 male. An "=" in the Kill-count columns indicates the individual puma selected prey in proportion

5 to selection exhibited by the population, a "+" indicates the puma selected a prey more than the

6 population, and a "_“ indicates that the individual selected a particular prey less than the

7 population as a whole.

\begin{tabular}{llccc}
\hline \multirow{2}{*}{ Puma } & Prey & $\begin{array}{c}\text { Bonf Z } \\
\text { Lower } \\
\text { Limit }\end{array}$ & $\begin{array}{c}\text { Bonf Z } \\
\text { Upper } \\
\text { Limit }\end{array}$ & Kill-count \\
\hline F013 & Elk & 0.886 & 1.043 & $0.779(+)$ \\
& Deer & -0.003 & 0.003 & $0.124(-)$ \\
& Moose & -0.043 & 0.114 & $0.038(=)$ \\
F018 & Pronghorn & -0.003 & 0.003 & $0.005(-)$ \\
& Bighorn & -0.003 & 0.003 & $0.054(-)$ \\
& Elk & 0.265 & 0.902 & $0.779(=)$ \\
F027 & Deer & 0.029 & 0.638 & $0.124(=)$ \\
& Moose & -0.006 & 0.006 & $0.038(-)$ \\
& Pronghorn & -0.006 & 0.006 & $0.005(=)$ \\
F047 & Bighorn & -0.095 & 0.262 & $0.054(=)$ \\
& Elk & 0.592 & 1.074 & $0.779(=)$ \\
& Deer & -0.095 & 0.262 & $0.124(=)$ \\
& Moose & -0.006 & 0.006 & $0.038(-)$ \\
& Pronghorn & -0.006 & 0.006 & $0.005(=)$ \\
& Bighorn & -0.006 & 0.006 & $0.054(-)$ \\
& Elk & 0.758 & 1.089 & $0.779(=)$ \\
& Deer & -0.089 & 0.243 & $0.124(=)$ \\
& Deer & -0.052 & 0.263 & $0.124(=)$ \\
& Moose & -0.005 & 0.006 & $0.038(-)$ \\
& Pronghorn & -0.005 & 0.006 & $0.005(=)$ \\
& Bighorn & -0.005 & 0.006 & $0.054(-)$ \\
& Elk & 0.580 & 1.198 & $0.779(=)$ \\
& & -0.004 & 0.004 & $0.038(-)$ \\
& Mighorn & -0.052 & 0.263 & $0.054(=)$ \\
& 0.315 & 1.019 & $0.779(=)$ \\
& Monghn & & &
\end{tabular}




\begin{tabular}{|c|c|c|c|c|}
\hline & Deer & -0.124 & 0.346 & $0.124(=)$ \\
\hline & Moose & -0.008 & 0.008 & $0.038(-)$ \\
\hline & Pronghorn & -0.008 & 0.008 & $0.005(=)$ \\
\hline & Bighorn & -0.124 & 0.346 & $0.054(=)$ \\
\hline \multirow[t]{5}{*}{ F051 } & Elk & 0.659 & 0.932 & $0.779(=)$ \\
\hline & Deer & -0.006 & 0.188 & $0.124(=)$ \\
\hline & Moose & -0.002 & 0.002 & $0.038(-)$ \\
\hline & Pronghorn & -0.028 & 0.073 & $0.005(=)$ \\
\hline & Bighorn & -0.006 & 0.188 & $0.054(=)$ \\
\hline \multirow[t]{5}{*}{ F057 } & Elk & 0.600 & 1.000 & $0.779(=)$ \\
\hline & Deer & -0.059 & 0.160 & $0.124(=)$ \\
\hline & Moose & -0.004 & 0.004 & $0.038(-)$ \\
\hline & Pronghorn & -0.004 & 0.004 & $0.005(-)$ \\
\hline & Bighorn & -0.029 & 0.329 & $0.054(=)$ \\
\hline \multirow[t]{5}{*}{ F061 } & Elk & 0.639 & 0.949 & $0.779(=)$ \\
\hline & Deer & 0.051 & 0.361 & $0.124(=)$ \\
\hline & Moose & -0.002 & 0.002 & $0.038(-)$ \\
\hline & Pronghorn & -0.002 & 0.002 & $0.005(-)$ \\
\hline & Bighorn & -0.002 & 0.002 & $0.054(-)$ \\
\hline \multirow[t]{5}{*}{ F069 } & Elk & 0.507 & 0.901 & $0.779(=)$ \\
\hline & Deer & -0.024 & 0.247 & $0.124(=)$ \\
\hline & Moose & -0.044 & 0.118 & $0.038(=)$ \\
\hline & Pronghorn & -0.005 & 0.301 & $0.005(=)$ \\
\hline & Bighorn & -0.003 & 0.003 & $0.054(-)$ \\
\hline \multirow[t]{5}{*}{ F101 } & Elk & 0.867 & 1.015 & $0.779(+)$ \\
\hline & Deer & -0.022 & 0.100 & $0.124(-)$ \\
\hline & Moose & -0.024 & 0.063 & $0.038(=)$ \\
\hline & Pronghorn & -0.001 & 0.001 & $0.005(-)$ \\
\hline & Bighorn & -0.001 & 0.001 & $0.054(-)$ \\
\hline \multirow[t]{5}{*}{ F102 } & Elk & 1.000 & 1.000 & $0.779(+)$ \\
\hline & Deer & -0.006 & 0.006 & $0.124(-)$ \\
\hline & Moose & -0.006 & 0.006 & $0.038(-)$ \\
\hline & Pronghorn & -0.006 & 0.006 & $0.005(=)$ \\
\hline & Bighorn & -0.006 & 0.006 & $0.054(-)$ \\
\hline \multirow[t]{5}{*}{ F104 } & Elk & 1.000 & 1.000 & $0.779(+)$ \\
\hline & Deer & -0.004 & 0.004 & $0.124(-)$ \\
\hline & Moose & -0.004 & 0.004 & $0.038(-)$ \\
\hline & Pronghorn & -0.004 & 0.004 & $0.005(-)$ \\
\hline & Bighorn & -0.004 & 0.004 & $0.054(-)$ \\
\hline \multirow[t]{2}{*}{ F109 } & Elk & 0.645 & 0.902 & $0.779(=)$ \\
\hline & Deer & -0.015 & 0.128 & $0.124(=)$ \\
\hline
\end{tabular}




\begin{tabular}{|c|c|c|c|c|}
\hline & Moose & -0.001 & 0.0014 & $0.038(-)$ \\
\hline & Pronghorn & -0.023 & 0.061 & $0.005(=)$ \\
\hline & Bighorn & 0.041 & 0.261 & $0.054(=)$ \\
\hline \multirow[t]{5}{*}{ M21 } & Elk & 0.338 & 0.721 & $0.779(-)$ \\
\hline & Deer & 0.011 & 0.283 & $0.124(=)$ \\
\hline & Moose & 0.144 & 0.503 & $0.038(+)$ \\
\hline & Pronghorn & -0.002 & 0.002 & $0.005(-)$ \\
\hline & Bighorn & -0.002 & 0.002 & $0.054(-)$ \\
\hline \multirow[t]{5}{*}{ M28 } & Elk & 0.384 & 0.880 & $0.779(=)$ \\
\hline & Deer & -0.004 & 0.004 & $0.124(-)$ \\
\hline & Moose & 0.121 & 0.616 & $0.038(+)$ \\
\hline & Pronghorn & -0.004 & 0.004 & $0.005(-)$ \\
\hline & Bighorn & -0.004 & 0.004 & $0.054(-)$ \\
\hline \multirow[t]{5}{*}{ M29 } & Elk & 0.837 & 1.034 & $0.779(+)$ \\
\hline & Deer & -0.002 & 0.002 & $0.124(-)$ \\
\hline & Moose & -0.034 & 0.163 & $0.038(=)$ \\
\hline & Pronghorn & -0.002 & 0.002 & $0.005(-)$ \\
\hline & Bighorn & -0.002 & 0.002 & $0.054(-)$ \\
\hline \multirow[t]{5}{*}{ M53 } & Elk & 0.467 & 1.088 & $0.779(=)$ \\
\hline & Deer & -0.008 & 0.008 & $0.124(-)$ \\
\hline & Moose & -0.088 & 0.533 & $0.038(=)$ \\
\hline & Pronghorn & -0.008 & 0.008 & $0.005(=)$ \\
\hline & Bighorn & -0.008 & 0.008 & $0.054(-)$ \\
\hline \multirow[t]{5}{*}{ M62 } & Elk & 1.000 & 1.000 & $0.779(+)$ \\
\hline & Deer & -0.007 & 0.007 & $0.124(-)$ \\
\hline & Moose & -0.007 & 0.007 & $0.038(-)$ \\
\hline & Pronghorn & -0.007 & 0.007 & $0.005(=)$ \\
\hline & Bighorn & -0.007 & 0.007 & $0.054(-)$ \\
\hline \multirow[t]{5}{*}{ M68 } & Elk & 1.000 & 1.000 & $0.779(+)$ \\
\hline & Deer & -0.014 & 0.014 & $0.124(-)$ \\
\hline & Moose & -0.014 & 0.014 & $0.038(-)$ \\
\hline & Pronghorn & -0.014 & 0.014 & $0.005(=)$ \\
\hline & Bighorn & -0.014 & 0.014 & $0.054(-)$ \\
\hline \multirow[t]{5}{*}{ M101 } & Elk & 0.573 & 0.973 & $0.779(=)$ \\
\hline & Deer & -0.003 & 0.003 & $0.124(-)$ \\
\hline & Moose & 0.0271 & 0.427 & $0.038(=)$ \\
\hline & Pronghorn & -0.003 & 0.003 & $0.005(-)$ \\
\hline & Bighorn & -0.003 & 0.003 & $0.054(-)$ \\
\hline
\end{tabular}




\section{Figure legends}

11 Figure 1. Results and 95\% CIs of Ivlev's analysis of winter prey selection by the puma (Puma

12 concolor L., 1771) population, as determined with the prey-count method to determine prey

13 availability.

14

15 Figure 2. Results of Levin's analyses of puma (Puma concolor L., 1771) niche breadths in

16 summer, and Levin's and Hulbert's analyses for winter. The black points denote the means with

17 associated 95\% CIs, and the gray points represent DDIs for individual pumas. Any individual

18 puma with a DDI that fell outside the CIs were determined to exhibit a niche breadth different

19 than the population as a whole.

20

21 


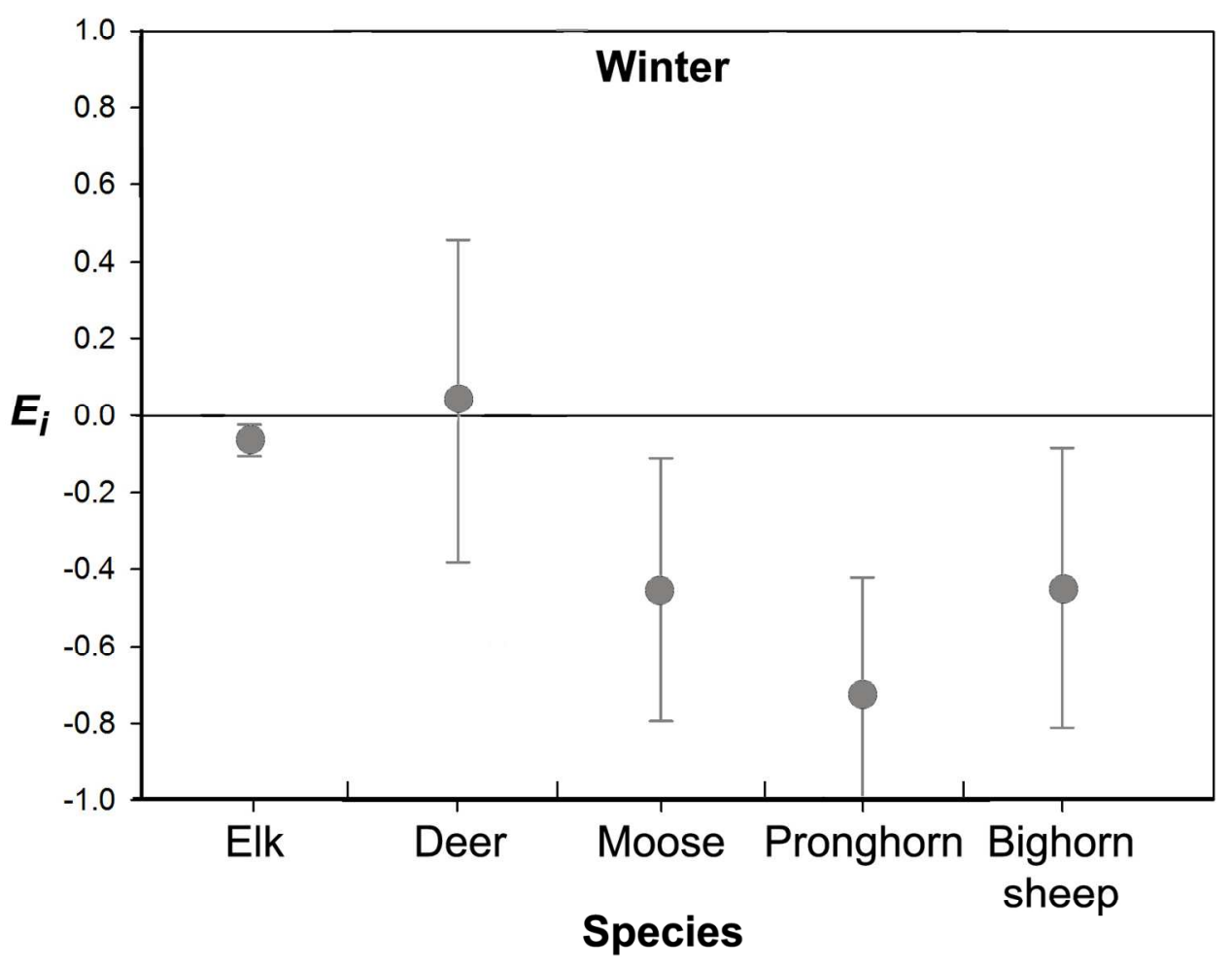

Figure 1. Results and 95\% CIs of Ivlev's analysis of winter prey selection by the puma (Puma concolor L., 1771) population, as determined with the prey-count method to determine prey availability. $145 \times 128 \mathrm{~mm}(300 \times 300 \mathrm{DPI})$ 

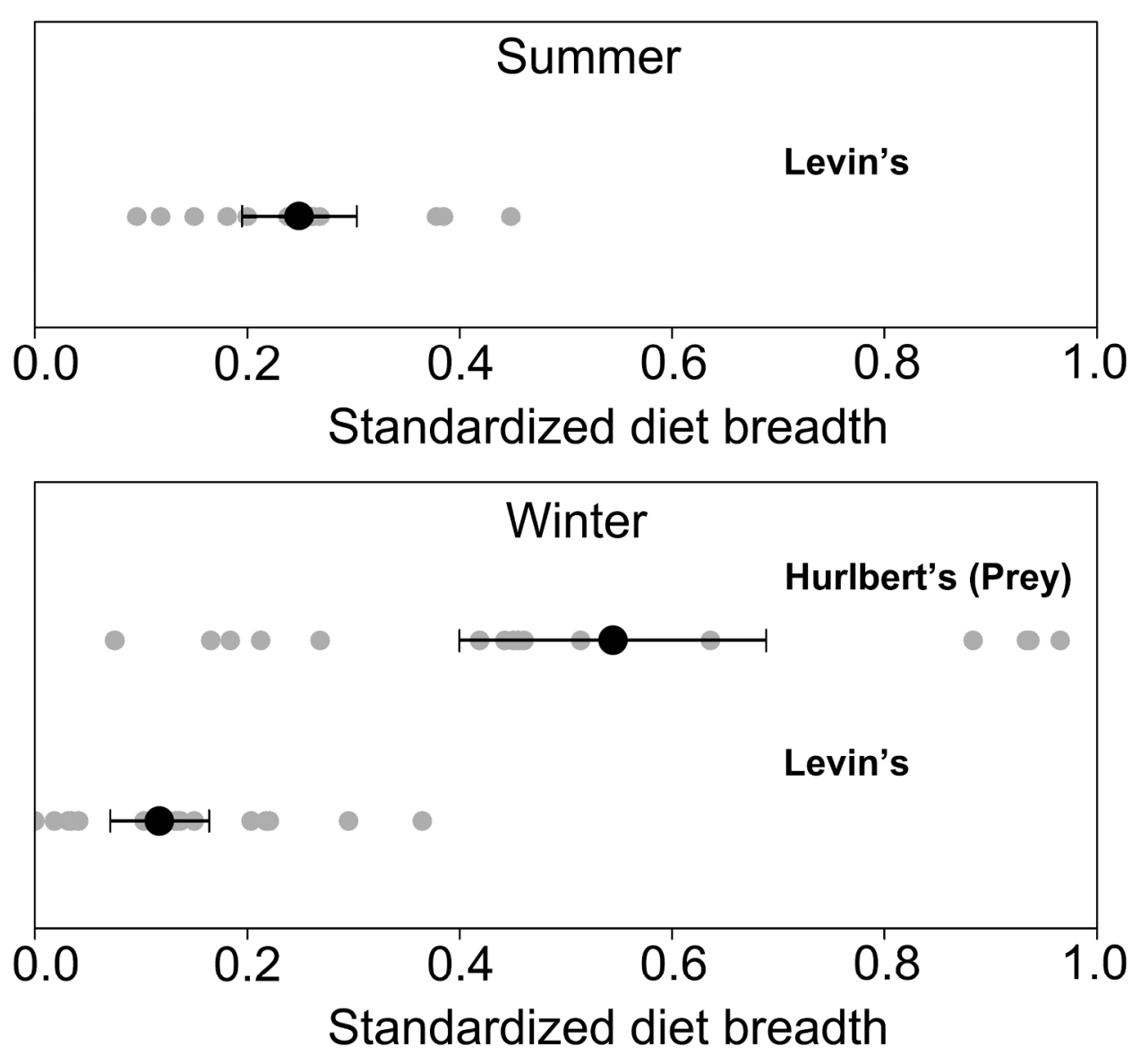

Results of Levin's analyses of puma niche breadths in summer, and Levin's and Hulbert's analyses for winter. The black points denote the means with associated $95 \%$ CIs, and the gray points represent DDIs for individual pumas. Any individual puma with a DDI that fell outside the CIs were determined to exhibit a niche breadth different than the population as a whole.

$201 \times 194 \mathrm{~mm}(300 \times 300 \mathrm{DPI})$ 